\title{
ORAL HYGIENE LEVELS IN PRIMARY MOLARS RESTORED WITH PREFORMED METAL CROWNS
}

\author{
Evgeni Dimitrov \\ Department of Pediatric Dentistry, Faculty of Dental Medicine, \\ Medical University of Varna
}

\begin{abstract}
INTRODUCTION: The choice of restoration material, the general health of the individual, and the distribution of caries in the different age groups is related to the level and the assessment of oral hygiene. In the treatment plan for these patients a preventive regime is necessary to be added, which includes instructions for oral hygiene improvement.

AIM: The aim of this article is to examine the level of oral hygiene in primary molars restored with preformed metal crowns (PMCs) and glass-ionomer cement (GIC).

MATERIALS AND METHODS: Object of the clinical study were 100 teeth with approximal dentin lesions on primary molars in 5- to 7-year-old children. The plaque index (PI) and the gingival index (GI) of SilnessLöe were used.

RESULT: In the current study, Silness-Löe PI was assessed before PMC/GIC application, on the $6^{\text {th }}$ month and after the first year of GIC/PMC placement. Around teeth restored with GIC more dental plaque was observed compared with the crowned teeth. PI was 1.35 for the filled teeth and 0.97 for the crowned ones. In both cases we reported moderate plaque accumulation and fair oral hygiene in the area of the first and second primary molar. The higher value of PI in the teeth restored with GIC was due to the higher rate of the minor failures of the fillings, which leads to plaque accumulation. There was no statistically significant difference in the GI for the GIC/PMC restorations at the 6th month and the first year after their application $(\mathrm{p}>0.05)$.
\end{abstract}

CONCLUSION: As a result, we concluded that PI for the teeth with PMCs was lower compared with the one in the natural control group of teeth. However, the average values of GI were significantly higher for the teeth with PMCs.

Keywords: PMCs, GIC, primary molars, plaque index, gingival index

\section{Address for correspondence: \\ Evgeni Dimitrov \\ Faculty of Dental Medicine \\ Medical University of Varna \\ 84 Tzar Osvoboditel Blvd \\ 9002 Varna \\ e-mail:eugene_d@abv.bg}

Received: September 21, 2019

Accepted: December 7, 2019

\section{INTRODUCTION}

The choice of restoration material, the general health of the individual, and the distribution of the caries in the different age groups is in direct connection with the level and the assessment of the oral hygiene (1-7).

Many studies give evidences regarding the gingival health on crowned teeth. Gotto (8) reports of 
cases of gingivitis on primary molars restored with nickel-chrome crowns. He found that the rate of gingivitis on crowned teeth is higher in the distal area compared with the frontal one as well as in cases of crowns which are not properly fit. The author found no evidence of gingivitis on the control group of teeth. In a study, Henderson (9) reported that the plaque accumulation on crowned teeth is lower compared with the ones without crowns in the other areas of the oral cavity. The level of marginal inflammation at crowns considered with "good" or "fair" adaptation is statistically equal, while those with "bad" adaptation are with higher rate of gingivitis. No information is given about the control group of teeth in this survey.

Webber (10) did not find significant changes in the gingiva after preformed metal crown (PMC) placement. Myers (11) indicated a close connection between gingival inflammation and bad adapted crowns. Paunio et al. (12) assessed the condition of the gingiva in 208 pairs of teeth for a 6-month period - 104 crowned teeth and 104 control teeth (86 of them restored with amalgam). A thickening of the marginal gingiva at a number of crowned teeth was established. The result from the average gingival index resembled the one from the control group of teeth on the second and the $6^{\text {th }}$ month of the follow-up. Durr et al. (13) examined 101 crowns on primary teeth, 95 of which were assessed as "defective". The reason for this was the observed gap between the crown and the tooth surface. However, the crowns were clinically functional and well accepted. The gingival index and the plaque accumulation at crowned teeth did not have any significant difference from the control group of teeth (14).

The measurement of the volume of the gingival liquid around 50 primary crowned molars showed identical levels with 50 control symmetrical teeth without crowns in all individuals with good oral hygiene regardless of the quality of crown adaptation. Patients with bad oral hygiene showed an increase in the level of gingival liquid (15). When evaluating for a 3-year period 118 PMCs on primary teeth and 70 on permanent first molars, compared with adjacent control teeth without crowns, it was clinically observed that there was fair gingival irritation of the gingiva around primary molars with PMCs. Deepened sul- cus was reported for the permanent teeth with PMCs of patients at 15 years of age (16).

In summary, the range of the plaque accumulation and the frequency of gingival inflammation related to PMCs on primary teeth looked insignificant (17). A well-adapted crown margin in the marginal area provides good oral hygiene and healthy gingiva $(16,18)$. The gingivitis may occur if the crown margins are inadequately trimmed $(8,9,11,19)$ or when there are cement residues in contact with the gingival sulcus $(17,19)$. The properties of the fixing agent - thickness and microleakage also affect the adaptation, the resistance, and the longevity of the restoration in the oral cavity (20). The "good" and "fair" adaptation seemed to cause minimal gingival irritation or plaque accumulation $(9,10,11,13,16)$ The patients who are with high caries risk with severely destroyed teeth or show high rate of plaque accumulation and food residues in the gingival area are indicated for restoration with PMCs. In the treatment plan for these patients a preventive regime is necessary to be added, which includes instructions for oral hygiene improvement $(9,18,21)$.

\section{AIM}

The aim of this article is to examine the level of oral hygiene in primary molars restored with PMCs and GIC.

\section{MATERIALS AND METHODS}

Object of the clinical study were 100 teeth with approximal dentin lesions on primary molars in 5to 7-year-old children from Varna who visited the Faculty of Dental Medicine and the University Dental Center. Fifty of them were restored with GIC and the other 50 were crowned teeth. Unit of observation was the dental plaque and localized gingival inflammation around the restoration. The plaque index (PI) of Silness-Löe is intended for plaque thickness measurement in the marginal gingiva. The gingival index (GI) serves as evaluation of the severity of the gingival inflammation in the areas affected by it. An atraumatic periodontal probe was used for the purposes of the study and visual evaluation of the condition of the gingival tissues around the restored primary molars. 


\section{RESULTS}

In the current study Silness-Löe PI was assessed before PMC/GIC application, on the $6^{\text {th }}$ month, and after the first year of GIC/PMC placement (Table 1). The results showed that before the treatment with GIC/PMC, a significant plaque accumulation was observed around the teeth. The children at 5-7 years of age, in addition to a high percentage caries distribution on the primary molars, also had bad oral hygiene in the distal areas of the dentition. On the sixth month after the restoration, the average value of PI was 0.90 for teeth restored with GIC and 0.74 for crowned ones (Fig. 1). This lower value of PI was due not only to the restoration itself but also to the elimination of the retentive area (the carious defect), as well as to the motivation of the patients to maintain better oral hygiene. One year after GIC/ PMC placement, the plaque index was higher compared to the one on the $6^{\text {th }}$ month. Around teeth restored with GIC more dental plaque was observed compared with the crowned teeth. PI was 1.35 for the filled teeth and 0.97 for the crowned ones (Fig. 1). In both cases we reported moderate plaque accu-

\section{PI no Silness-Löe}

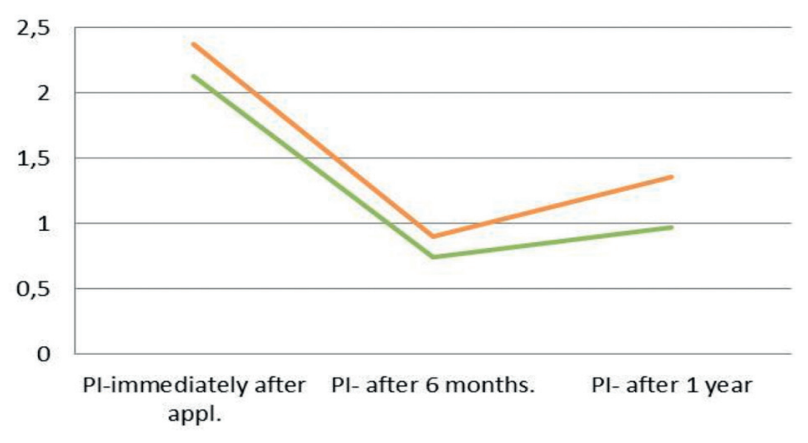

Fig. 1. Comparison of the average values of PI of Silness Löe on $6^{\text {th }}$ and $12^{\text {th }}$ month on teeth restored with GIC and PMCs mulation and fair oral hygiene in the area of the first and second primary molar. There was no statistically significant difference in PI on the $6^{\text {th }}$ month and the first year after the restoration $(p>0.05)$. The higher value of PI in teeth restored with GIC was due to the higher rate of minor failures of the fillings, which led to plaque accumulation. The results showed that at the first year the necessity of remotivation for better oral hygiene was clearly noticeable.

The value of GI of Löe-Silness, immediately after the application of GIC/PMC on molars liable for treatment, was high (Table 2). At the $6^{\text {th }}$ month after the restorations, due to elimination of the retentive areas and the instruction for oral hygiene, drop rate was observed in the values of GI for GIC - 0.74, as well as for PMCs -0.63 (Fig. 2). On the $12^{\text {th }}$ month an increased average value was observed - for teeth restored with GIC - 1.13, and for those with PMCs - 1.19 (Fig. 2). This was related to the minor failures (partial or total loss of the restoration), which GIC suffered as they created new retentive areas and conditions for plaque accumulation. Remotivation was

\section{GI- no Löe- Silness}

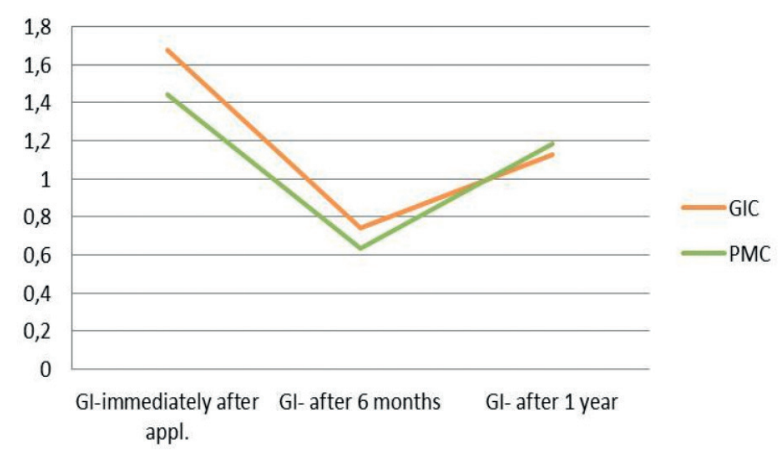

Fig. 2. Comparison of the average values of GI of LöeSilness on $6^{\text {th }}$ and $12^{\text {th }}$ month for teeth restored with GIC and PMCs

Table 1. Average value of the plaque index on teeth restored with GIC and PMC, reported immediately after the treatment, on the $6^{\text {th }}$ month and on the $1^{\text {st }}$ year

\begin{tabular}{lcc}
\hline & GIC & PMC \\
Plaque index immediately after application & 2.37 & 2.13 \\
Plaque index after 6 months & 0.90 & 0.74 \\
Plaque index after 1 year & 1.35 & 0.97 \\
& $\mathrm{t}_{1,2}=1.087 ; \mathrm{p}<0.05$ & \\
T-test; P value & $\mathrm{t}_{1,3}=0.961 ; \mathrm{p}<0.05$ & \\
& $\mathrm{t}_{2,3}=0.9501 ; \mathrm{p}<0.05$ & \\
\hline
\end{tabular}


necessary for oral hygiene improvement. According to many literature articles the irritation of the gingiva on teeth restored with PMCs is related to poor adaptation of the crown as it was placed without previous preparation of the teeth. The residues from GIC in the gingival sulcus may also become a reason for irritation in the marginal area. In addition, the crown's margin in the cervical area created conditions for plaque accumulation, but this was not the main reason for the gingival inflammation. There was no statistically significant difference in GI for the restorations of GIC/PMCs on the $6^{\text {th }}$ month and the first year after their application ( $>0.05)$ (Table 2).
In 2011 (27), the plaque index on primary molars, restored with GIC, was registered. The results were reported immediately after the application of the cement and 2 years after. The average value of the plaque index, 2 hours after the restoration, was $2.26 \pm 0.46$. After 2 years the index was $1.9 \pm 2.1$. A total of $76.6 \%$ of the children had plaque index on the restored molars above 1.5. The data in the literature about plaque index on teeth restored with GIC are insufficient. In the same survey (27) it was reported that the average value of the plaque index got higher due to failed restorations. There have been many studies regarding the adaptation of preformed met-

Table 2. Average value of the gingival index on teeth restored with GIC and PMC, reported immediately after the treatment, on the $6^{\text {th }}$ month and on the $1^{\text {st }}$ year

\begin{tabular}{lcc} 
& GIC & PMC \\
Gingival index immediately after the treatment & 1.68 & 1.45 \\
Gingival index after 6 months & 0.74 & 0.63 \\
Gingival index after 1 year & 1.13 & 1.19 \\
& $\mathrm{t}_{1,2}=2.117 ; \mathrm{p}<0.05$ & $\mathrm{t}_{2,3}=1.171 ; \mathrm{p}=0.05$ \\
T- test; P value & $\mathrm{t}_{1,3}=1.262 ; \mathrm{p}<0.05$ \\
\hline
\end{tabular}

\section{DISCUSSION}

These results confirmed the results from many other literature articles, where no comparison of the accumulated dental plaque was found for teeth restored with GIC and PMCs $(22,23,24)$.

Chao, Tsai and Chen (25) reported that the accumulated plaque on the surface of the preformed metal crowns was lower compared to the one on the natural teeth.

In 2014 (26), a survey compared the plaque index on teeth restored with conventional filling materials and the Hall technique. It was established that $59 \%$ of the children with conventional restorations and $64 \%$ of the children treated with the Hall technique had excellent oral hygiene one year after the treatment. From the treated patients 36\% with GIC and $34 \%$ with PMCs had PI = 1 (fair oral hygiene). Barely $5 \%$ of the children with conventional fillings and $2 \%$ of the children with the Hall technique had $\mathrm{PI}=2$ (bad oral hygiene). Most of the patients with failures of the restoration had plaque index higher than 0 . al crowns in the gingival area, including the current one. The results we got were close to the ones reported by many other articles. Randall (24), in 2000, reported that there was no difference in the values of sOHI Green-Vermilion comparing teeth restored with PMCs and symmetrical natural teeth. Beldüz Kara and Yilmaz (28) established that the gingival index for teeth restored with a preformed metal crown for primary molars was always higher compared with the one in the control group of teeth. Koth (29) reported that the crown restorations had the potential to cause gingival inflammation, but it can be controlled in motivated patients and regular visitations in the dental office.

Jeng-Fen Liu examined 102 teeth with preformed metal crowns. $66.7 \%$ of them were with gingival inflammation. For comparison, in the control group the teeth with gingival inflammation were $37.3 \%$. However, the author claimed that the teeth with preformed metal crowns accumulated less plaque than the natural ones (30). A survey conducted in 2014 (26) did not report significant changes in the gingival index. Object of examination were 
primary molars with conventional fillings and Hall crowned teeth. One year after the treatment GI $=0$ was reported for $93 \%$ of the patients with conventionally treated teeth and $84 \%$ of those restored with Hall crowns. In $7 \%$ of the patients treated with the conventional methods and $16 \%$ with the Hall technique a gingival index $=1$ was reported. None of the examined children was with GI $=2$. The data in the literature concerning the values of PI and GI around the different fillings compared with those around PMCs is insufficient.

\section{CONCLUSION}

As a result, we concluded that the plaque index for the teeth with preformed metal crowns was lower compared with the index in the natural control group of teeth. However, the average values of the gingival index were significantly higher for the teeth with PMCs. The higher values of the gingival index were due to defects in the restoration - irritation from the crown's margin and bad adaptation of the crown in the gingival area. This may be a reason for plaque accumulation as it comes as aggravating factor concerning the gingival inflammation in this area.

\section{REFERENCES}

1. Georgieva M, Andreeva R. Caries distribution by teeth groups among 12-18-year-old children in Varna. Varna Med Forum.2018;7(1): 131-5.

2. Nikolova $T$, Andreeva R. Prevalence of dental decay among children suffering from congenital heart diseases. Scr Sci Med Dent. 2018;4(2):22-5.

3. Nikolova T, Andreeva R, Georgieva M, Shivachev P. Prevalence of dental decay and periodontal diseases among children suffering from congenital heart diseases. A literature review - Part III. Scr Sci Med Dent, 2018;4(1):7-11.

4. Nikolova T, Andreeva R, Georgieva M, Shivachev P. Prevalence of dental decay and periodontal diseases among children suffering from congenital heart diseases. A literature review-part II. Scr. Sci. Med. Dent. 2017;3(2):48-55.

5. Nikolova $T$, Andreeva R, Georgieva M, Shivachev P. Prevalence of dental decay and periodontal diseases among children suffering from congenital heart diseases. A literature review-part I. Scr Sci Med Dent. 2017;3(2):36-40.
6. Miteva M, Sabeva E, Georgieva I, Hristov I. Erbium lasers in periodontology. Scr Sci Med Dent. 2017; 3(1):7-11.

7. Miteva M, Peev S, Sabeva E, Hristov I. Clinical Evaluation of Nd:YAGlaser applications during nonsurgical periodontal treatment in patients with chronic periodontitis. Int J Sci Res (IJSR). 2017;6(4):57 - 60 .

8. Goto G, Imanishi T, Machida Y. Clinical evaluation of preformed crown for deciduous teeth. Bull Tokyo Dent Coll. 1970;11(3):169-76.

9. Henderson HZ. Evaluation of the preformed stainless steel crown. ASDC J Dent Child. 1973;40(5):353-81.

10. Webber DL. Gingival health following placement of stainless steel crowns. ASDC J Dent Child. 1974;41(3):186-9.

11. Myers DR. A clinical study of the response of the gingival tissue surrounding stainless steel crowns. ASDC J Dent Child. 1975;42(4):281-4.

12. Paunio P, Eriksson A-L, Isotupa K. Suitability of ion-crowns for the restoration of deciduous molars. Proc Finn Dent Soc. 1980;76(1):25-29.

13. Durr DP, Ashrafi MH, Duncan WK. A study of plaque accumulation and gingival health surrounding stainless steel crowns. ASDC J Dent Child. 1982;49(5):343-6.

14. Doichinova L. Risk assessment for the development of caries in visually impaired children in Sofia city, Bulgaria. Int J Sci Res (IJSR). 2015; 4(2): 1108-11.

15. Checchio LM, Gaskill WF, Carrel R. The relationship between periodontal disease and stainless steel crowns. ASDC J Dent Child. 1983;50(3):205-9.

16. Einwag J. Effect of entirely preformed stainless steel crowns on periodontal health in primary, mixed dentitions. ASDC J Dent Child. 1984;51(5):356-9

17. Fayle SA. UK national guidelines in pediatric dentistry. Int J Pediatr Dent. 1999;9(4):311-4.

18. Duggal MS, Curzon MEJ, Fayle SA, Pollard MA, Robertson AJ. Restorative Techniques in Paediatric Dentistry. 1st ed. London: Martin Dunitz; 1995.

19. More FG, Pink TC. The stainless steel crown: A clinical guide. J Mich State Dent Assoc. 1973;55(15):237-42.

20. Georgieva-Dimitrova M. Laboratory examination of cement thickness for zirconia and composite inlays cemented with two types of fixing agents. Scr Sci Med Dent. 2019;5(1):47-51. 
21. Georgieva-Dimitrova M. Case report: the Hall technique as a method of choice in case of asymptomatic closed pulpitis in primary teeth. Scr Sci Med Dent. 2019;5(1):52-8.

22. AAPD Clinical guideline on pediatric restorative dentistry. Pediatr Dent. 2004;26:106-14.

23. Litonjua LA, Cabanilla LL, Abbott LJ. Plaque formation and marginal gingivitis associated with restorative materials. Compend Contin Educ Dent. 2011;32(4):e69-72.

24. Randall RC. Preformed metal crowns for primary and permanent molar teeth: review of the literature. Pediatr Dent. 2002;24(5):489-500.

25. Chao DD, Tsai TP, Chen TC. Clinical evaluation of gingival tissue restored with stainless steel crown. Changgeng Yi Xue Za Zhi. 1992;15(4):198-203.

26. Santamaria RM, Innes NP, Machiulskiene V, Evans DJ, Splieth CH. Caries management strategies for primary molars: 1-yr randomized control trial results. J Dent Res. 2014;93(11):1062-9.
27. Arthur M. Kemoli, Willem E. Van Amerongen. Effects of oral hygiene, residual caries and cervical Marginal-gaps on the survival of proximal atraumatic restorative treatment approach restorations. Contemp Clin Dent. 2011; 2(4): 318-23.

28. Beldüz Kara N, Yilmaz Y. Assessment of oral hygiene and periodontal health around posterior primary molars after their restoration with various crown types. Int J Paediatr Dent. 2014;24(4):303-13.

29. Koth DL. Full crown restorations and gingival inflammation in a controlled population. J Prosthet Dent. 1982;48(6):681-5.

30. Liu Jeng-Fen. Stainless steel crown restoration and gingivitis on primary molar. Chin Dent J. 2002;21:43-8. 